\title{
Avaliação do potencial antiaderente do óleo de lavanda contra cepa de Escherichia coli
}

Evaluation of the non-stick potential of lavender oil against Escherichia coli strain

Evaluación del potencial antiadherente del aceite de lavanda frente a la cepa de Escherichia coli

Filipe de Oliveira Lima ORCID: https://orcid.org/0000-0001-6652-3101 Universidade Federal de Campina Grande, Brasil

E-mail: filipelimaoliveirava@outlook.com

Thallita Alves dos Santos

ORCID: https://orcid.org/0000-0002-7100-5023

Universidade Federal de Campina Grande, Brasil

E-mail: thallita_28@hotmail.com

Maria Tays Pereira Santana

ORCID: https://orcid.org/0000-0002-6503-7117

Universidade Federal de Campina Grande, Brasil

E-mail: taayssantana@gmail.com

Sheyliane Rego Morais

ORCID: https://orcid.org/0000-0002-7567-5892

Universidade Federal de Campina Grande, Brasil

E-mail: sheylianerego@gmail.com

Lucas Linhares Gomes

ORCID: https://orcid.org/0000-0001-6626-4824

Universidade Federal de Campina Grande, Brasil

E-mail: lucaslinharesg@ @otmail.com

Laís Sousa Maia

ORCID: https://orcid.org/0000-0003-1742-8989

Universidade Federal de Campina Grande, Brasil

E-mail: laissousahmaia@gmail.com

Natália Oliveira Matos

ORCID: https://orcid.org/0000-0001-6590-6901

Universidade Federal de Campina Grande, Brasil

E-mail: nataliaomatos@gmail.com

Maria Ruhama Ferreira Alves

ORCID: https://orcid.org/0000-0002-1022-1312

Universidade Federal de Campina Grande, Brasil

E-mail: ruhamaferreira@hotmail.com

Quemuel Pereira da Silva

ORCID: https://orcid.org/0000-0002-0093-6322

Universidade Federal de Campina Grande, Brasil

E-mail: quemuelpereira7@gmail.com

Paula Lima Nogueira

ORCID: https://orcid.org/0000-0001-7425-3201

Universidade Federal de Campina Grande, Brasil

E-mail: paulalimanogueira@hotmail.com

Fabiana Larissa Santos de Medeiros

ORCID: https://orcid.org/0000-0002-3804-600X

Universidade Federal de Campina Grande, Brasil

E-mail: fabiana.serido@hotmail.com

Rosana Araújo Rosendo

ORCID: https://orcid.org/0000-0002-3795-8832

Universidade Federal de Campina Grande, Brasil

E-mail: cesprodonto@hotmail.com

Maria Angélica Sátyro Gomes Alves

ORCID: https://orcid.org/0000-0003-3329-8360

Universidade Federal de Campina Grande, Brasil E-mail: angelicasatyro@hotmail.com

Luciano de Brito Júnior

ORCID: https://orcid.org/0000-0002-1787-4316

Universidade Federal de Campina Grande, Brasil

E-mail: lbritojunior@hotmail.com 


\title{
Resumo
}

Terapias endodônticas convencionais utilizam instrumentos mecânicos e soluções irrigadoras para promover a descontaminação dos canais; porém, a presença de bactérias mais resistentes e com maior capacidade de aderência às paredes dentinárias acaba levando ao desenvolvimento de infecções secundárias. Hodiernamente, ocorrem grandes avanços nas pesquisas científicas com uso de produtos naturais visto que extratos e óleos de diversas plantas possuem propriedades antimicrobianas e afetam o biofilme. O presente trabalho avaliou o potencial antiaderente do óleo essencial de Lavandula hybrida Grosso contra cepa de Escherichia coli. Para isto, foram realizadas: a avaliação da Concentração Inibitória Mínima de Aderência (CIMA) do óleo contra cepa de E. coli e a comparação da potência antiaderente do óleo com a clorexidina $0,12 \%$. Os ensaios foram realizados utilizando a técnica de tubos inclinados para determinação da CIMA ao vidro, na presença de 5\% de sacarose. Observou-se que o óleo apresentou CIMA de $1: 16$, enquanto que o controle positivo (digluconato de clorexidina 0,12\%) apresentou CIMA de 1:8. Nota-se que foi necessário uma concentração duas vezes menor do óleo para inibir a adesão da bactéria à parede do tubo em comparação com o principal antisséptico químico usado em tratamentos odontológicos. Conclui-se que o óleo em questão mostra-se apto para desenvolvimento de soluções irrigadoras dos canais radiculares ou ainda de ser empregado como substância irrigadora auxiliar, pois apresenta capacidade de inibir a aderência de Escherichia coli, uma das bactérias que compõe o biofilme patogênico encontrado nas infecções endodônticas secundárias.

Palavras-chave: Endodontia; Fitoterapia; Microbiologia.

\begin{abstract}
Conventional endodontic therapies use mechanical instruments and irrigation solutions to promote canal decontamination; however, the presence of more resistant bacteria and greater capacity to adhere to the dental walls ends up leading to the development of secondary infections. Currently, great advances in scientific research using natural products occur, since extracts and oils from different plants have antimicrobial properties and affect biofilm. The present work evaluated the non-stick potential of Lavandula hybrida Grosso essential oil against Escherichia coli strain. For this, the following were carried out: the evaluation of the Minimum Inhibitory Concentration of Adhesion (MICA) of the oil against E. coli strain and the comparison of the oil's non-stick potency with $0.12 \%$ chlorhexidine. The tests were performed using the inclined tube technique to determine the MICA on the glass, in the presence of 5\% sucrose. It was observed that the oil showed a 1:16 MICA, while the positive control $(0.12 \%$ chlorhexidine digluconate) presented a 1:8 MICA. It is noted that a twice lower oil concentration is necessary to inhibit the adhesion of the bacteria to the tube wall compared to the main chemical antiseptic used in dental treatments. It is concluded that the oil in question is suitable for the development of irrigation solutions of the root canals or to be used as an auxiliary irrigation substance, as it has the ability to inhibit the adhesion of Escherichia coli, one of the bacteria that makes up the pathogenic biofilm found in secondary endodontic infections.
\end{abstract}

Keywords: Endodontics; Phytotherapy; Microbiology.

\section{Resumen}

Las terapias de endodoncia convencionales utilizan instrumentos mecánicos y soluciones de irrigación para promover la descontaminación del canal; sin embargo, la presencia de bacterias más resistentes y con mayor capacidad de adherirse a las paredes dentinarias acaba provocando el desarrollo de infecciones secundarias. En la actualidad, existen grandes avances en las investigaciones científicas utilizando productos naturales ya que los extractos y aceites de varias plantas tienen propiedades antimicrobianas y afectan el biofilm. El presente trabajo evaluó el potencial antiadherente del aceite esencial de Lavandula hybrida Grosso contra la cepa de Escherichia coli. Para ello se llevó a cabo la evaluación de la Concentración Inhibitoria Mínima de Adherencia (CIMA) del aceite frente a la cepa de $E$. coli y la comparación de la potencia antiadherente del aceite con clorhexidina al 0,12\%. Los ensayos se realizaron mediante la técnica de tubos inclinados para determinar la CIMA sobre vidrio, en presencia de sacarosa al 5\%. Se observó que el aceite tenía una CIMA de 1:16, mientras que el control positivo (gluconato de clorhexidina al 0,12\%) tenía una CIMA de 1: 8. Cabe señalar que se necesitaba una concentración dos veces menor de aceite para inhibir la adhesión de las bacterias a la pared del tubo en comparación con el principal antiséptico químico utilizado en los tratamientos dentales. Se concluye que el aceite en cuestión es apto para el desarrollo de soluciones de riego para conductos radiculares o incluso para ser utilizado como sustancia auxiliar de riego, ya que tiene la capacidad de inhibir la adherencia de Escherichia coli, una de las bacterias que componen la biopelícula patógena que se encuentra en las infecciones endodónticas secundarias.

Palabras clave: Endodoncia; Fitoterapia; Microbiología. 


\section{Introdução}

As doenças que afetam o sistema de canais radiculares são provenientes de derivados metabólicos gerados por microrganismos. Assim, para que se consiga êxito no tratamento endodôntico, é fundamental que ocorra uma boa desinfecção química e mecânica dos condutos radiculares. Para isso, é essencial diminuir a contaminação bacteriana instigando o organismo frente ao controle e reparação dos danos causados (Pestana, 2016).

A união de diversos microrganismos, compondo uma intricada matriz que pode estar aderida tanto a superfícies bióticas quanto abióticas recebe o nome de biofilme, o qual é constituído também por várias camadas de componentes orgânicos produzidos por esses microrganismos ou adquiridos do meio em que se encontram estabelecidos (Bazargani \& Rohloff, 2015). O insucesso no tratamento endodôntico possui como fator predominante a persistência de microrganismos no sistema de condutos radiculares. Isso é explicado devido à presença de biofilme nos canais acessórios, istmos e túbulos dentinários; lugares de difícil acesso para a instrumentação mecânica, por soluções irrigadoras e medicações intracanal (Lacerda, Coutinho, Barrocas, Rodrigues \& Vidal, 2016). Em meio a essa relação simbiótica, o grupo das bactérias é comumente identificado possuindo um importante papel na manutenção do biofilme e encontrando nessa associação uma forma bastante vantajosa de aumentar a sua resistência aos agentes antimicrobianos (Stewart \& Consternon, 2001).

Dentro desse grupo de bactérias, a Escherichia coli faz parte do conjunto de microrganismos que estão associados às infecções secundárias envolvendo patologias endodônticas. Essa bactéria, possui endotoxinas que, ao serem liberadas, promovem a indução de vários efeitos biológicos que levam a uma resposta inflamatória exarcebada (Brito, 2010).

Lacerda et al. (2016) conclui em seu trabalho falando da necessidade do desenvolvimento de novas técnicas de desinfecção e de novas medicações para proporcionar cada vez mais um tratamento endodôntico presumível e eficiente, e ainda ressalta a importância da realização de estudos para que se identifiquem os tipos de microrganismos responsáveis pelas infecções e seus mecanismos de ação.

$\mathrm{Na}$ atualidade, tem se destacado um grande avanço nas pesquisas científicas na área de produtos de origem natural, os quais apresentam inúmeros compostos e propriedades antimicrobianas (Valera et al., 2013). Dentre esses produtos pode se observar que muitos tipos de extratos e óleos essenciais de diversas espécies de plantas apresentam uma ação de grande efetividade sobre o biofilme e a placa bacteriana (Bazargani \& Rohloff, 2015).

Com base nisso, muitos estudos são realizados para avaliar a aplicabilidade de extratos e óleos essenciais de plantas. Dentre elas, a Lavanda vem despertando bastante interesse na indústria de cosméticos e, principalmente, na farmacêutica devido a presença de substâncias e compostos com potencial antimicrobiano (Cavanagh \& Wilkinson, 2002; Andriolli, 2014). As plantas de Lavanda fazem parte da família Lamiaceae, uma das maiores do grupo das Angiospermas, e do gênero Lavandula que engloba mais de 30 espécies diferentes.

Esse gênero compreende plantas com bastante aroma e pubescentes, do tipo herbáceas, de caráter perene, arbustivas ou subarbustivas, tendo o verão como a época mais propícia para o seu florescimento. Suas hastes são lenhosas e geralmente ramificadas. Possuem ramos nus, eretos ou que se desenvolvem de forma ascendente, tomentosos e simples. O formato quadrado ou retangular, que é considerado característico das plantas do gênero é facilmente visto ao se efetuar um corte transversal nas hastes florais. A cor das folhas é acinzentada quando a planta ainda é jovem, tornando-se verde na fase adulta, a disposição das folhas é de forma oposta, com formato linear ou oblongo-lanceolado, estreitas e inteiras, com bordas inteiras ou denteadas, apresentando medidas de 5 à $6 \mathrm{~cm}$ de comprimento por 0,4 à $0,5 \mathrm{~cm}$ de largura. $\mathrm{O}$ fruto da lavanda é um aquênio e as sementes, pequenas, são de cor preta, lisa, e exalam o mesmo perfume característico da planta (Mcgimpsey \& Porter, 1999).

A planta do tipo Lavanda tem altura entre 0,5 e 0,8 metros, podendo ultrapassar 1 metro em algumas espécies. O clima e a região possuem influência direta no desenvolvimento das plantas, visto que plantas em condições de pouca umidade ou plantas crescendo em regiões de altas temperaturas médias desenvolvem-se com menor porte e produzem inflorescências 
em quantidades mais baixas. Como em outras culturas, a densidade de plantio também influencia o porte das plantas (Mcgimpsey \& Porter, 1999). Entre as principais variedades do gênero Lavandula está a Grosso que possui em sua composição monoterpenos tais como o linalol e acetato de linalila, além de ser a mais cultivada na região do Mediterrâneo (Andriolli, 2014; Mcgimpsey \& Porter, 1999; Panizza \& Tognoni, 1988; Donadu et al., 2018).

Segundo Tardugno et al. (2017) o óleo essencial de Lavandula é bastante cobiçado aos olhos da indústria farmacêutica pelo fato de ser avaliado como um ótimo agente antimicrobiano, com comprovação verificada em pesquisas científicas contra bactérias Gram-negativas e Gram-positivas. Além disso, num estudo realizado por Medeiros et al. (2019) foi observado que o óleo essencial de Lavandula hybrida Grosso possui um potencial de ação antibacteriano contra a Escherichia coli. Nesse estudo foi visto que o óleo essencial em questão apresentava um poder inibitório de crescimento contra essa espécie de bactéria considerado moderado.

Os estudos realizados no ramo da Fitoterapia contribuem para o desenvolvimento de medicamentos e tratamentos com menores custos e realizados em um menor período de tempo proporcionando a população uma maior acessibilidade. De acordo com informações do próprio sistema público de saúde, cerca de $25 \%$ das medicações disponíveis advém de forma direta ou indireta de plantas medicinais, que são atestadas segundo a Organização Mundial da Saúde (OMS) como as melhores fontes de angariar produtos terapêuticos e medicinais (Santos et al., 2019; Luchesi, 2017).

Diante do exposto, o presente estudo objetivou avaliar o potencial antiaderente do óleo essencial de Lavandula hybrida Grosso contra cepa de Escherichia coli usando para isso a análise da sua Concentração Inibitória Mínima de Aderência (CIMA).

\section{Metodologia}

\subsection{Ensaios in vitro}

\subsubsection{Local da pesquisa}

A pesquisa foi realizada no laboratório de Microbiologia da Unidade Acadêmica de Ciências Biológicas do Centro de Saúde e Tecnologia Rural da Universidade Federal de Campina Grande.

\subsubsection{Substância teste}

O óleo essencial de Lavandula hybrida Grosso foi adquirido da Indústria Via Aroma (Porto Alegre - RS).

\subsubsection{Espécie bacteriana e meio de cultura}

Foi utilizada a bactéria de origem clínica: Escherichia coli (EC102 - cepa clínica). A cepa foi mantida em meio Ágar Muller Hinton (AMH) a uma temperatura de $4{ }^{\circ} \mathrm{C}$, sendo utilizados para os ensaios repiques de 24 horas em AMH incubados a $35^{\circ} \mathrm{C}$.

\subsubsection{Determinação da Concentração Inibitória Mínima (CIMA)}

A Concentração Inibitória Mínima de Aderência (CIMA) do óleo foi determinada na presença de sacarose a 5\%, de acordo com Alburqueque et al. (2010), usando-se concentrações correspondentes do óleo essencial puro até a diluição 1:1024. A partir do crescimento bacteriano, a cepa de Escherichia coli 102 foi cultivada a $37{ }^{\circ} \mathrm{C}$ em caldo Mueller Hinton (DIFCO, Michigan, Estados Unidos), depois foram distribuídos $0,9 \mathrm{ml}$ do subcultivo em tubos de ensaio e, em seguida, adicionado 0,1 $\mathrm{ml}$ da solução correspondente às diluições do óleo essencial. A incubação foi feita a $37^{\circ} \mathrm{C}$ por 24 horas com tubos inclinados a $30^{\circ}$. A leitura foi realizada através da observação visual da aderência da bactéria às paredes do tubo, após a agitação do mesmo. 
O ensaio foi realizado em duplicata. O mesmo procedimento foi realizado para o controle positivo, o digluconato de clorexidina a $0,12 \%$ (Periogard®, Colgate-Palmolive Company, Nova York, EUA). Foi considerada a CIMA a menor concentração do agente em contato com sacarose que impediu a aderência ao tubo de vidro.

\section{Resultados e Discussão}

A utilização de fitoterápicos pode ajudar no combate e tratamento de inúmeras doenças, podendo ser administrados conjuntamente ou não com medicações de origem alopática e desde que sejam prescritos adequadamente e de acordo com as necessidades de cada paciente, eles devem e podem ser disponibilizados para o uso em Odontologia (Aleluia et al., 2015).

Os estudos realizados com plantas medicinais vêm demonstrando uma abrangente e diversificada gama de propriedades, com destaque especial para as suas capacidades antioxidante, anti-inflamatória e antimicrobiana, tornando-as de grande relevância para a sua aplicação clínica (Jain \& Ranjan, 2014; Oliveira et al., 2016; Tewari, Kapoor, Mishra \& Kumar, 2016). Dentre os produtos naturais fornecidos pelas plantas tem se os óleos essenciais que são advindos do seu metabolismo secundário e que apresentam em sua formulação compostos aromáticos voláteis (Miranda, Cardoso, Batista, Rodrigues \& Figueiredo, 2016).

$\mathrm{Na}$ tabela 1 estão descritos os resultados acerca da atividade antiaderente do óleo essencial de Lavandula hybrida Grosso contra a cepa de Escherichia coli, assim como sua comparação com o digluconato de clorexidina 0,12\%.

Tabela 1: Concentração Inibitória Mínima de Aderência (CIMA) em $\mu \mathrm{g} / \mathrm{mL}$ do óleo essencial de Lavandula hybrida Grosso e do digluconato de clorexidina $0,12 \%$ contra cepa de Escherichia coli.

\begin{tabular}{|c|c|c|}
\hline $\begin{array}{l}\text { Tipo de substância: } \\
\text { em } \mu \mathrm{g} / \mathrm{mL} \text { : }\end{array}$ & $\begin{array}{c}\text { Óleo essencial de } \\
\text { Lavandula hybrida Grosso }\end{array}$ & $\begin{array}{c}\text { Digluconato de } \\
\text { clorexidina 0,12\% }\end{array}$ \\
\hline $1: 1$ & - & - \\
\hline $1: 2$ & - & - \\
\hline $1: 4$ & - & + \\
\hline $1: 8$ & - & + \\
\hline $1: 16$ & - & + \\
\hline $1: 32$ & + & + \\
\hline $1: 64$ & + & + \\
\hline
\end{tabular}

Legenda: (-) Sem adesão à parede do tubo (+) Com adesão à parede do tubo. Fonte: Autoria própria.

No resultado obtido no estudo foi observado que o óleo essencial de Lavandula hybrida Grosso apresentou uma CIMA de 1:16, enquanto o controle positivo (digluconato de clorexidina 0,12\%) apresentou uma CIMA de 1:8, ou seja, pode se inferir que foi necessária uma concentração duas vezes menor do óleo essencial para inibir a adesão da bactéria à parede do tubo em comparação com a do principal antisséptico químico usado em tratamentos odontológicos.

A clorexidina é considerada como sendo o padrão ouro para a realização de testes de potência de agentes antimicrobianos, já que ela apresenta uma ótima eficácia e consiste no agente antimicrobiano de origem sintética mais potente e estudado (Hortense et al., 2010). O amplo espectro de ação desse tipo de solução, que age sobre microrganismos Gram + e Gram -, é apenas uma das muitas propriedades que ela possui, podendo-se citar ainda sua alta substantividade, sua segurança e 
sua eficácia comprovada como agente antimicrobiano (Marion, Pavan, Arruda, Nakashima \& Morais, 2013). Apesar de apresentar boa substantividade, uma revisão de literatura realizada por Mohammadi, Jafarzadeh e Shalavi (2014) mostra que essa substância deve ser recomendada como enxaguante final do sistema de canais radiculares, mas não sendo aconselhável seu uso como o irrigante principal, devido principalmente a sua dificuldade de dissolução de tecidos.

De acordo com Souza et al. (2019) que estudou o potencial antibacteriano e antiaderente do óleo essencial de Lavandula hybrida Grosso contra cepas de Klebisiella pneumoniae realizando a determinação da Concentração Inibitória Mínima de Aderência (CIMA) e comparando-a com o controle digluconato de clorexidina a 0,12\% foi visto que a capacidade antimicrobiana do óleo era elevada contra a bactéria e o seu potencial antiaderente, na sua menor concentração, demonstrou significativa inibição do biofilme bacteriano com valor da CIMA de 1:32.

Um outro estudo envolvendo a E. coli e K. pneumoniae foi realizado por Bajalan et al. (2017) e avaliou a atividade de óleos essenciais de lavandas híbridas contra essas espécies de bactérias sendo verificado nos resultados que a atividade inibitória era de intensidade moderada.

Ainda sobre a atuação de óleos essenciais sobre cepas de bactérias, Ramalho et al. (2020) desenvolveu um estudo, valendo-se da mesma metodologia adotada por este presente trabalho, para avaliar a atividade antiaderente dos óleos essenciais de plantas do gênero Eucalyptus contra cepas de Klebsiela pneumoniae e observou que o óleo de Eucalyptus globulus apresentou uma boa eficiência antiaderente contra essa bactéria, demonstrando inibição da formação do biofilme na concentração 1:8 sendo equivalente ao controle digluconato de clorexidina 0,12\%. Já Santana et al. (2020) avaliou a atividade antimicrobiana do óleo essencial de Lavandula hybrida Grosso associado ao antimicrobiano gentamicina contra cepas de Staphylococcus aureus e verificou um efeito sinérgico dos compostos, ratificando assim uma importância terapêutica desse óleo.

$\mathrm{Na}$ busca pelo desenvolvimento de uma solução irrigadora para canais radiculares utilizando o extrato de plantas medicinais do semiárido, Silva (2018) constatou a presença de altos teores de polifenóis totais e taninos condensados nos extratos estudados, e que isso estaria diretamente associado à sua atividade antimicrobiana. Foi visto também que o extrato vegetal ao ser adicionado em outras formulações manteve a sua atividade antibacteriana, mesmo com a variação dos parâmetros físico-químicos. Sendo, portanto, de importante valia para o controle de qualidade do produto o uso de marcadores químicos.

Sendo assim, é possível deduzir que muitos dos compostos bioativos encontrados nas plantas e em seus subprodutos, tal é o caso dos óleos essenciais, podem servir como uma nova opção aos irrigadores tradicionais (como, por exemplo, o hipoclorito de sódio) para o tratamento endodôntico ou como substância auxiliar das soluções já existentes (Silva, 2018; Freires \& Rosalen, 2016).

\section{Conclusão}

A partir dos resultados obtidos nesse estudo podemos concluir que o óleo essencial de Lavandula hybrida Grosso se mostra como um forte candidato para o desenvolvimento de uma solução irrigadora do sistema de canais radiculares ou ainda passível de ser empregado como substância irrigadora auxiliar, já que esse apresenta capacidade de inibir a aderência de Escherichia coli, que é uma das bactérias presentes na composição do biofilme patogênico encontrado nos casos de infecção endodôntica secundária. No entanto, ainda são necessários mais estudos sobre as características desse produto fitoterápico e suas propriedades físico-químicas para verificar e avaliar os níveis de interação dele com os outros tipos de materiais utilizados no procedimento endodôntico. 


\section{Agradecimentos}

Os autores agradecem à Universidade Federal de Campina Grande e à toda equipe que faz parte da Liga Acadêmica de Fitoterapia, Bioquímica e Microbiologia Bucal - LAFBIM/UACB/UFCG por toda a colaboração no desenvolvimento deste trabalho e pesquisa científica. Agradecimento especial ao Professor Doutor Abrahão Alves de Oliveira Filho por todo apoio na realização desta pesquisa.

\section{Referências}

Albuquerque, A. C. L., Pereira, M. S. V., Pereira, J. V., Pereira, L. F., Silva, D. F., Macedo-Costa, M. R., \& Higino, J. S. (2010). Efeito antiaderente do extrato da Matricaria recutita Linn. sobre microorganismos do biofilme dental. Rev. Odontol. UNESP, 39(1), 21-25.

Aleluia, C. M., Procópio, V. C., Oliveira, M. T. G., Furtado, P. G. S., Giovannini, J. F. G., \& Mendonça, S. M. S. (2015). Fitoterápicos na odontologia. Rev. Odontol. Univ. Cid. São Paulo (Online), 27(2), 126-134. doi: 10.26843/ro_unicid.v27i2.263.

Andriolli, B. V. (2014). Micropropagação de Lavanda (Lavandula x intermedia Emeric ex Loisel., Lamiceae) variedade Grosso para extração de óleo essencial. 2014. 24f. Trabalho de Conclusão de Curso (Graduação) - Curso em Ciências Rurais, Universidade Federal de Santa Catarina.

Bajalan, I., Rouzbahani, R., Pirbalouti, A. G., \& Maggi, F. (2017). Chemical composition and antibacterial activity of Iranian lavandula $\times$ hybrida. Chem. Biodivers., 14(7), e1700064. doi: 10.1002/cbdv.201700064.

Bazargani, M. M., \& Rohloff, J. (2015). Antibiofilm activity of essential oils and plant extracts against Staphylococcus aureus and Escherichia coli biofilms. Food Control, 61(2016), 156-164. doi: 10.1016/j.foodcont.2015.09.036.

Brito, E. G. (2010). Efeitos in vitro de extratos naturais sobre o Enterococcus faecalis, Staphylococcus aureus, Escherichia coli e endotoxinas em canais radiculares. 2010. 130 f. Dissertação (Mestrado) - Pós-graduação em Biopatologia Bucal, Faculdade de Odontologia de São José dos Campos, Universidade Estadual Paulista.

Cavanagh, H. M. A., \& Wilkinson, J. M. (2002). Biological activities of Lavender essential oil. Phytother. Res., 16(4), 301-308. doi: 10.1002/ptr.1103.

Donadu, M., Usai, D., Pinna, A., Porcu, T., Mazzarello, V., Fiamma, M., Marchetti, M., Cannas, S., Degolu, G., Zanetti, S., \& Molicotti, P. (2018). In vitro activity of hybrid lavender essential oils against multidrug resistant strains of Pseudomonas aeruginosa.J. Infect. Dev. Ctries., 12(1), 9-14. doi: $10.3855 /$ jidc. 9920 .

Freires, I. A., \& Rosalen, P. L. (2016). How natural product research has contributed to oral care product development? A Critical Review. Pharm Res., 33, 1311-1317. doi: 10.1007/s11095-016-1905-5.

Hortense, S. R., Carvalho, E. S., Carvalho, F. S., Silva, R. P. R., Bastos, J. R. M., \& Bastos, R. S. (2010). Uso da clorexidina como agente preventivo e terapêutico na odontologia. Rev. Odontol. Univ. Cid. São Paulo (Online), 22(2),178-184. doi: 10.26843/ro_unicid.v22i2.414.

Jain, P., \& Ranjan, M. (2014). Role of herbs in root canal irrigation: A review. IOSR J. Pharm. Biol. Sci., 9(2), 06-10. doi: 10.9790/3008-09260610.

Lacerda, M. F. L. S., Coutinho, T.M., Barrocas, D., Rodrigues, J. T., \& Vidal, F. (2016). Infecção secundária e persistente e sua relação com o fracasso do tratamento endodôntico. Rev. bras. odontol., 73(3), 212-217. doi: 10.18363/rbo.v73n3.p.212.

Luchesi, L. A. (2017). Atividade antibacteriana, antifúngica e antioxidante de óleos essenciais. 2017.88 f. Dissertação (Mestrado) - Pós-graduação em Agroecossistemas, Universidade Tecnológica Federal do Paraná.

Marion, J., Pavan, K., Arruda, M. E. B. F., Nakashima, L., \& Morais, C. A. H. (2013). Chlorhexidine and its applications in Endodontics: a literature review. Dent. Press. Endod., 3(3), 36-54.

Mcgimpsey, J. A., \& Porter, N. G. (1999). Lavender: A Growers' Guide for Commercial Production. 2nd ed., New Zealand: New Zealand Institute for Crop \& Food Research Limited.

Medeiros, M. A. A., Alves, M. S., Simão, K. L. A., Pereira, C. T., Simão, B. L. A., Pessoa, H. L. F., Diniz, M. F. F. M., \& Oliveira Filho, A. A. (2019). Avaliação da atividade antibacteriana do óleo essencial de Lavandula hybrida Grosso contra cepas de Escherichia coli. Revista Saúde \& Ciência (Online), 8(2), 58-65. doi: 10.35572/rsc.v8i2.41.

Miranda, C. A. S. F., Cardoso, M. G., Batista, L. R., Rodrigues, L. M. A., \& Figueiredo, A. C. S. (2016). Óleos essenciais de folhas de diversas espécies: propriedades antioxidantes e antibacterianas no crescimento espécies patogênicas. Rev. Ciên. Agron., 47(1), 213-220. doi: 10.5935/1806-6690.20160025.

Mohammadi, Z., Jafarzadeh, H., \& Shalavi, S. (2014). Antimicrobial efficacy of chlorhexidine as a root canal irrigant: a literature review. J. Oral Sci., 56(2), 99-113. doi: 10.2334/josnusd.56.99.

Oliveira, C. L., Campos, L. T., Duarte, H. A., Bezerra, L. M. D., Brandt, L. M. T., Cardoso, A. M. R., Castro, R. D., \& Cavalcanti, A. L. (2016). Atividade antimicrobiana do óleo de copaifera officinalis sobre bactérias do biofilme oral. Rev. Ciênc. Méd. Biol., 15(1), 34-38. doi: 10.9771/cmbio.v15i1.14602.

Panizza, M., \& Tognoni, F. (1988). Clonal Propagation, Callus Formation and Plant Regeneration of Lavandin. Sci. Hortic., 37(1-2), 157-163. doi: $10.1016 / 0304-4238(88) 90158-6$.

Pestana, H. C. (2016). O uso da Própolis na Endodontia. 2016. 19f. Trabalho de Conclusão de Curso (Graduação) - Curso de Odontologia, Centro Universitário São Lucas. 
Research, Society and Development, v. 10, n. 8, e22810817225, 2021

(CC BY 4.0) | ISSN 2525-3409 | DOI: http://dx.doi.org/10.33448/rsd-v10i8.17225

Ramalho, M. A. S., Santos, B., Ramalho, D. F., Cunha, S. M. D., Anjos, R. M., Oliveira, H. M. B. F., Sousa, A. P., \& Oliveira Filho, A. A. (2020), Antiadherent activity of essencial oils of Eucalyptus globulus and Eucalyptus citriodora against Klebsiella pneumoniae strains. Res., Soc. Dev., 9(7), e. 406974245. doi: 10.33448/rsd-v9i7.4245.

Santana, M. T. P., Gomes, L. L., Santos, T. A., Lima, F. O., Moaris, S. R., Sousa, A. P., Alves, M. A. S. G., Guênes, G. M. T., Oliveira, H. M. B. F., \& Oliveira Filho, A. A. (2020). Atividade antibcteriana do óleo essencial da Lavandula Híbrida Grosso associada à gentamicina contra cepas de Staphylococcus aureus. Archives of Health Investigation, 9(4), 362-366. doi: 10.21270/archi.v9i4.5034.

Santos, E. P., Rodrigues, F. S., Santos, I. C. R. S., Silva, K. C. S., Coutinho, G. S. L., Firmo, W. C. A., \& Pinheiro, A. J. M. C. R. (2019). Punica Granatum L.(Romã) e Atividade Antimicrobiana Contra o Biofilme Dental: uma Revisão Bibliográfica. Ensaios e Ciênc., 23(2), 88-93. doi: 10.17921/14156938.2019v23n2p88-93.

Silva, A. F. (2018). Desenvolvimento de uma solução irrigadora de canais radiculares utilizando o extrato de plantas medicinais do semiárido. $2018.71 \mathrm{f}$. Dissertação (Mestrado) - Pós-graduação em Odontologia, Universidade Estadual da Paraíba.

Souza, E. R. L. (2019). Potencial antimicrobiano e antiaderente do óleo essencial de Lavandula Híbrida Grosso contra cepas de Klebsiella pneumoniae. 2019. 62 f. Trabalho de Conclusão de Curso (Graduação) - Curso de Odontologia, Centro de Saúde e Tecnologia Rural, Universidade Federal de Campina Grande.

Stewart, P. S., \& Costerton, J. W. (2001). Antibiotic resistance of bacteria in biofilms. Lancet, 358(9276), 135-138. doi: 10.1016/S0140-6736(01)05321-1.

Tardugno, R., Pellati, F., Iseppi, R., Bondi, M., Bruzzesi, G., \& Benvenuti, S. (2017). Phytochemical composition and in vitro screening of the antimicrobial activity of essential oils on oral pathogenic bacteria. Nat. Prod. Res., 32(5), 544-551. doi: 10.1080/14786419.2017.1329730.

Tewari, R. K., Kapoor, B., Mishra, S. K., \& Kumar, A. (2016). Role of herbs in endodontics. J. Oral Res. Rev., 8(2), 95-99. doi: 10.4103/2249-4987.192248.

Valera, M. C., Maekawa, L. E., Oliveira, L.D., Jorge, A. O. C., Shygei, E., \& Carvalho, C. A. T. (2013). In vitro antimicrobial activity of auxiliary chemical substances and natural extracts on Candida albicans and Enterococcus faecalis in root canals. J. Appl. Oral Sci., 21(2), 118-123. doi: 10.1590/16787757201302135. 